\title{
Modeling of available size selectivity of the SURF-BRD for shrimp beam trawl
}

\author{
Yoritake Kajikawa $\cdot$ Tadashi Tokai $\cdot$ \\ Fuxiang Hu
}

Received: 1 February 2013/ Accepted: 2 September 2013/Published online: 23 October 2013

(C) The Author(s) 2013. This article is published with open access at Springerlink.com

\begin{abstract}
The System of Unwants Ramp-way FilteredBycatch Reduction Device (SURF-BRD) was developed to reduce shrimp bycatch in a shrimp beam trawl. It consists of a pair of rectangular net panels, namely, the front panel (FP) and rear panel (RP), and two fish escape vents. In this study, numerical models for expressing available selection by the SURF-BRD were proposed and assessed in several fishing experiments conducted using two types of the BRD: a prototype and an improved type with the BRD attached at a higher point on the side-nets . Contact probability and selectivity parameters of the FP and the RP for four major species were estimated for each BRD type. The improved type with the higher BRD showed a larger contact probability for the FP. Size selectivity of the FP and RP for two species (cinnamon flounder and spotted swimming crab) was almost equivalent to the mesh selectivity of the net panel, but that for lizard fish seemed to depend not on mesh size of the FP but on the swimming behavior of the fish. These results suggest that the smaller mesh size of the RP would be helpful for releasing more fish of smaller size and to exclude more spotted swimming crab, which hinder ondeck sorting by fishermen.
\end{abstract}

\footnotetext{
Y. Kajikawa $(\bowtie)$

Department of Fisheries Science and Technology, National Fisheries University, 2-7-1 Nagata-Honmachi, Shimonoseki, Yamaguchi 759-6595, Japan

e-mail: kajikawa@ fish-u.ac.jp

T. Tokai - F. Hu

Graduate School of Marine Science and Technology, Tokyo

University of Marine Science and Technology, Minato,

Tokyo 108-8477, Japan
}

Keywords Shrimp beam trawl - Bycatch reduction device $\cdot$ Available selection model $\cdot$ Available size selectivity $\cdot$ Selection process

\section{Introduction}

Many studies on bycatch reduction devices (BRDs) in fishing gear used by commercial fisheries have been conducted in Japan, and fishing gear with newly developed BRDs are continuously being implemented by commercial fisheries [1-4]. The authors have developed two types (prototype and improved type) of the SURF (System of Unwants Ramp-way Filtered)-BRD for use by beam trawlers in the coastal waters off Shimonoseki, Yamaguchi Prefecture in western Japan [5-8]. The SURF-BRD comprises a front panel (FP) made of large mesh net and a rear panel (RP) made of fine mesh net, and both are assembled together in a mountain shape and attached as a unit to the lower part of the net mouth (Fig. 1). In both the prototype and improved type, the FP is made out of a square mesh net with a bar length of $40 \mathrm{~mm}$ (stretched inner mesh size of 72 $\mathrm{mm}$ ), and the RP is a diamond mesh with a stretched mesh size of $27.5 \mathrm{~mm}$. An escape vent, which is a triangleshaped cut-out, is made on each side of the net between the FP and the RP. In the fishing experiments, side-vent cover nets of the same mesh as the cod-end covers escape vents at both sides to catch animals exiting from the escape vents (Fig. 1). In earlier studies, the authors [6] confirmed that the prototype with the FP head-line $0.4 \mathrm{~m}$ high during towing had species selection such that target small shrimps were retained while small crabs of no commercial value were excluded from the net and that it also had size selectivity allowing small size fish to escape from the net. Each end of the FP head-line of the prototype was attached 
Fig. 1 Schematic diagram of small-scale trawl net to which the System of Unwants Rampway Filtered-Bycatch Reduction Device (SURF-BRD) is attached. Side-vent covers were attached in the fishing experiments to examine animals exiting from the escape vents

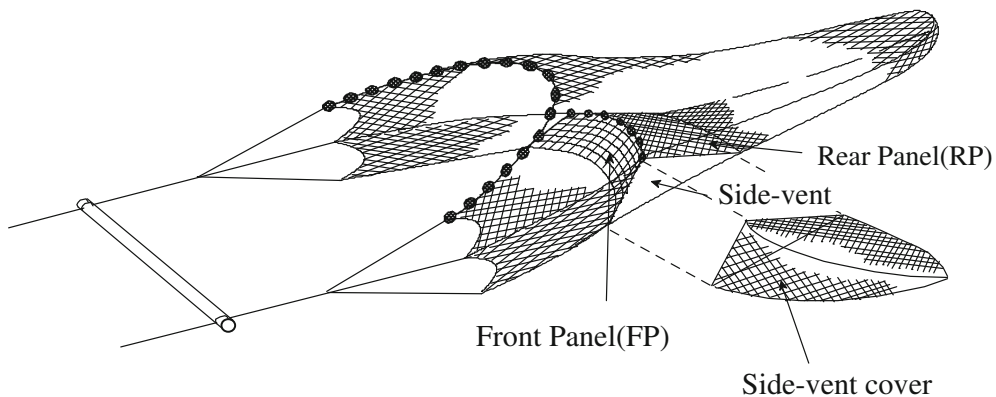

Side-vent cover at one-third of the height of the side net. Model experiments in a flume tank revealed that attachment of the FP head-lines at higher points at each end of the side net maintains the BRD in a more vertical position (taller) [7]. Accordingly, in the improved type, the FP is attached at one-half of the side net height on each side. As previous research [8] indicated, although the height of the SURFBRD in the prototype was set at about $0.4 \mathrm{~m}$, that in the improved type was set at about $1.8 \mathrm{~m}$. The higher BRD of the improved type allows lizard fish Saurida spp. and cinnamon flounder Pseudorhombus cinnamoneus to encounter the FP much more frequently than in the prototype, and therefore the size selection of the FP for these species is more effective [8]. Using the improved type, we found that the majority of whiskered velvet shrimp Matapenaeopsis barbata entering the net were retained in the cod-end, but that an increased number of spotted swimming crab Charybdis bimaculata passed through the FP and were then excluded through the side vent after being blocked by the RP mesh [8].

Quantitative assessment methods have been employed to analyze the separation effectiveness of the BRD, including the contact probability model developed by Tokai et al. [9], Tokai [10], and Zuur et al. [11]. The combination of contact selection and contact probability was termed the available selection model by Millar and Fryer [12]. This available selection model has been used to determine the separation of the grid separator $[13,14]$, the square mesh bycatch reduction window $[15,16]$, selectivity for the cod-end when the mesh of the cod-end is clogged by the catch [17], and the effect of the dredge tooth spacing on selectivity for bivalves [18, 19].

In the study reported here, we used catch data obtained in fishing experiments involving both the prototype and improved type of SURF-BRD and attempted to construct a numerical model for the available selection of the SURFBRD. In this context, we discuss the species- and sizeselection process of the SURF-BRD based on the estimated parameters of contact probability and selectivity curve in the available selection numerical model and evaluate the effect of BRD height on contact probability. The appropriate mesh size of the FP and the RP in the SURF$\mathrm{BRD}$ is also discussed in terms of fisheries management.

\section{Materials and methods}

Fishing experiments

In this study, catch data were obtained in a small beam trawl that was using two types of SURF-BRD: the prototype and the improved type where the vents at both sides are covered with vent-covers (Fig. 1). The beam trawler Dai San Kaikomaru (2.9 t) belonging to the Izaki Branch of the Yamaguchi Prefecture Fisheries Cooperative Association was chartered and operated in the coastal waters off Shimonoseki, Yamaguchi Prefecture in western Japan. A total of ten tows were conducted with the prototype on 1 July 1996 and on 8 and 10 September 1998, and a total of eight tows were conducted with the improved type on 29 and 30 June 2000. Each tow was conducted for $60 \mathrm{~min}$ during the night in areas with depths of 20-30 m. The mesh of the vent-cover was the same as that of the cod-end.

As previously reported [8], the heights of the net mouth and BRD had an influence on species- and size-selectivity by the FP and RP.Depth meters (MDS-TD; Alec Electronics, Japan; resolution $0.125 \mathrm{~m}$; precision $\mathrm{FS} \pm 0.5 \%$ ) were placed at the center of the head rope, the upper edge of the URF-BRD, and at foot rope to measure the heights of the net mouth and the BRD during towing. Data were recorded at 1-min intervals.

The catch from each tow was sampled from the cod-end and both side-vent covers on board the ship and brought back to the laboratory for follow-up measurement of length and weight. Body length was measured in millimeters on a fish body measuring board or in 0.1-mm increments with a digital caliper (SC-15S; Mitsutoyo, Kawasaki, Japan). Total length (TL) for fish, carapace length (CL) for shrimp, and maximum carapace width $(\mathrm{CW})$ for small crabs were measured. An electronic scale (BP6100; Sartorius, Goettingen, Germany; minimum readout $0.01 \mathrm{~g}$ ) was used for the measurement of body weight. 
Data for all individuals from each tow were pooled and analyzed. In our previous reports $[6,8]$, the data were separated between day and night, although the SURFBRD used in these tows was the same. In the present study, only data from tows done at night were used for the model analysis because this fishery usually operates at night.

Numerical models used for data analysis

This aim of this study was on selection provided by the SURF-BRD; cod-end selectivity was not evaluated because it could not be examined using the data obtained in the fishing experiments due to the same mesh size being used in both the cod-end and the vent-covers.

Here, we denote the number of fish with length $l$, passing through the net mouth by $N_{l}$. The probabilities of an animal coming in contact with the FP and RP are given by $p$ and $q$, respectively. We assume that size selection by the FP [expressed as $r_{\mathrm{F}}(l)$ ] and RP [expressed as $\left.r_{\mathrm{R}}(l)\right]$ can be calculated by the following logistic functions:

$r_{F}(l)=1 /\left[1+\exp \left(a_{F}+b_{F} l\right)\right]$ and

$r_{R}(l)=1 /\left[1+\exp \left(a_{R}+b_{R} l\right)\right]$,

where $\left(a_{\mathrm{R}}, b_{\mathrm{R}}\right)$ and $\left(a_{\mathrm{F}}, b_{\mathrm{F}}\right)$ are parameters of the logistic function for the FP and RP, respectively. As the mesh size of the FP is about threefold larger than that of the RP, the relationship of $r_{\mathrm{F}}(l)$ and $r_{\mathrm{R}}(l)$ are as follows:

$0 \leq r_{\mathrm{F}}(l) \leq r_{\mathrm{R}}(l) \leq 1$

In this study, the number of fish of a given $l$ passing through Paths 1-5 in the separation processes of SURF$\mathrm{BRD}$ is represented by the following equations (Fig. 2).
Path 1 Number of fish of given $l$ that do not come in contact with the FP and then are retained by the cod-end: $C_{1 l}=(1-p) N_{l}$

Path 2 Number of fish of given $l$ that come in contact with the FP but do not pass through the FP and then are retained by the cod-end: $C_{2 l}=p r_{\mathrm{F}}(l) N_{l}$

Path 3 Number of fish of given $l$ that pass through the FP but do not come in contact with the RP and then escape through the escape vent: $C_{3 l}=p(1-q)[1$ $\left.-r_{\mathrm{F}}(l)\right] N_{l}$

Path 4 Number of fish of given $l$ that pass through the FP but do not pass through the RP and then escape through the escape vent: $C_{4 l}=p q\left[1-r_{\mathrm{F}}(l)\right]$ $r_{\mathrm{R}}(l) N_{l}$

Path 5 Number of fish of given $l$ that pass through both the FP and RP and then are retained in the codend: $C_{5 l}=p q\left[1-r_{\mathrm{F}}(l)\right]\left[1-r_{\mathrm{R}}(l)\right] N_{l}$

Here, $N_{l}$ is the number of fish with length $l$ that enter the net and is equal to $C_{1 l}+C_{2 l}+C_{3 l}+C_{4 l}+C_{5 l}$. Individuals that pass through Paths 1, 2, and 5 in the SURF-BRD are retained in the cod-end, while those passing through Paths 3 and 4 escape through the side-vents into the vent-covers (Fig. 3). According to the SELECT method [20], the proportion of fish retained in the cod-end $\left(C_{1 l}+C_{2 l}+C_{5 l}\right)$ relative to the total number $N_{l}$ is described by the following equation:

$\phi_{l}=\left(C_{1 l}+C_{2 l}+C_{5 l}\right) / N_{l}$

As a function of $l, \phi_{0}(l)$ is described by the following equation:

$\phi_{0}(l)=(1-p)+p r_{F}(l)+p q\left[1-r_{F}(l)\right]\left[1-r_{R}(l)\right]$

The model of equation $\phi_{0}(l)$ for which all parameters are actualized $\left(0<p<1, \quad 0<q<1, \quad 0<r_{\mathrm{F}}(l)<1\right.$,
Fig. 2 Selective processes of SURF-BRD in the trawl net mouth

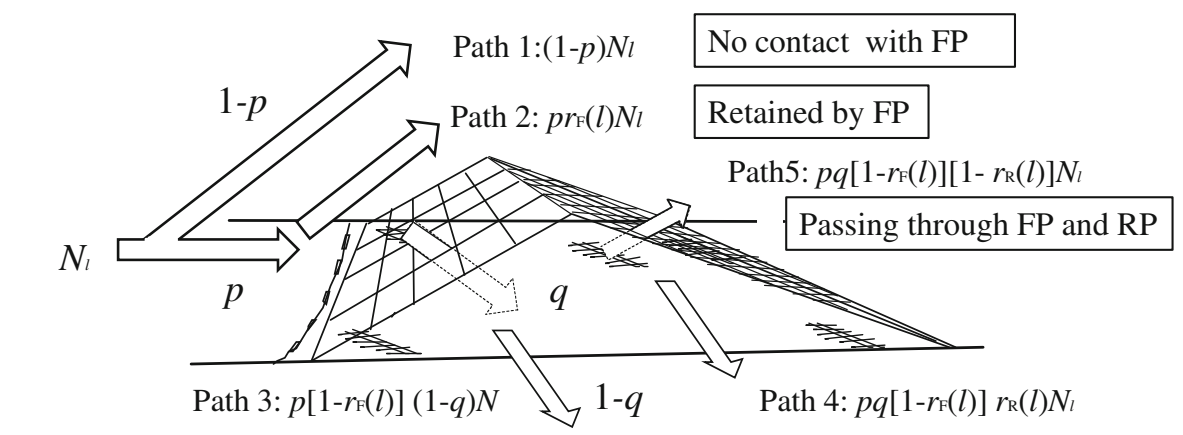

Passing through FP and no contact with RP

Passing through FP and retained by RP

$\begin{array}{ll}N l \text { : Number of fish with length } l \text { entering the net } & r_{\mathrm{F}}(l) \text { : Probability of fish contacting the FP } \\ p: \text { Probability of fish contacting the FP } & r_{\mathrm{R}}(l) \text { : Probability of fish contacting the RP } \\ q \text { : Probability of fish contacting the RP } & \end{array}$ 


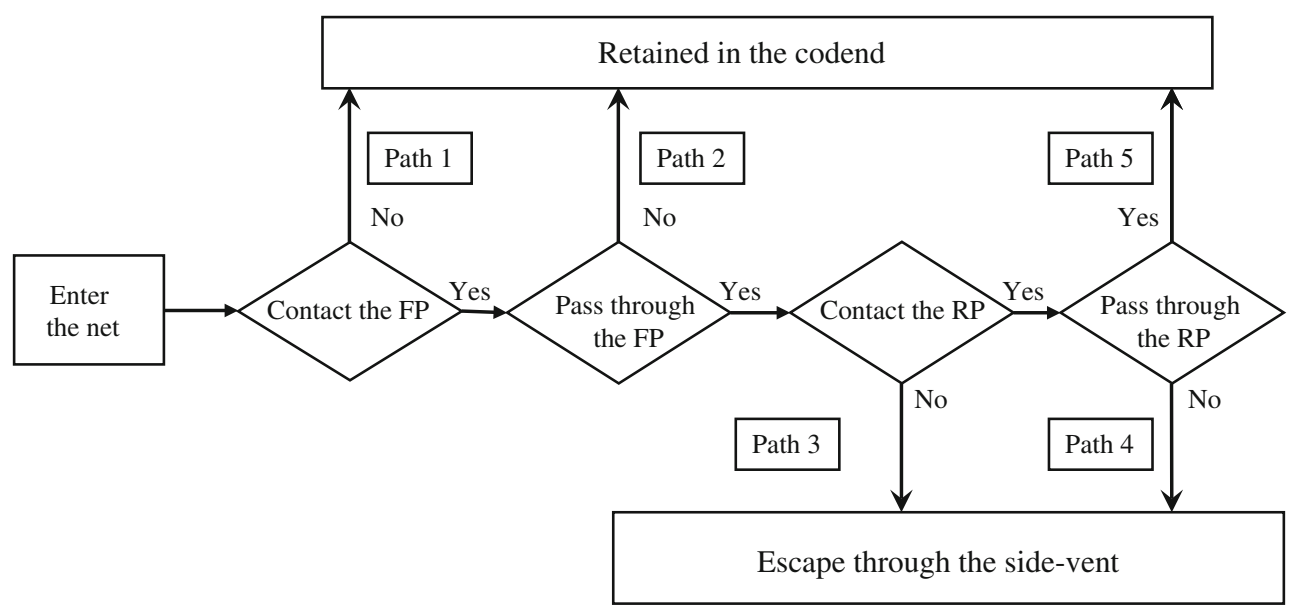

Fig. 3 Flow chart of the selective processes in the trawl net with the SURF-BRD

$\left.0<r_{\mathrm{R}}(l)<1\right)$ is hereafter called Model A. In Model A with $0<p<1,0<q<1$, plots of $\phi_{0}(l)$ against body length $l$ gives a $U$-shaped curve (Fig. 4) and all of the five paths are included. However, all parameters are not always actualized. For example, the contact selectivity of the FP against body length for all individuals becomes 1 when the fish body is too large to pass through the mesh of the FP. In this case, the contact selectivity parameters for the FP drop out of the equation. In this study, in accordance with the combination of $r_{\mathrm{F}}(l)=0$ and $r_{\mathrm{R}}(l)=1$ associated with the shape of the model curve, in addition to Model A we prepared three models (Models $\mathrm{B}, \mathrm{C}$, and D) having a $U$-shaped curve. Each of these models had some variations, depending on whether each of the two parameters $p$ and $q$ for contact probability were 1 or not. It is also noted that the parameter $p=1$ and $q=1$ excludes Path 1 and Path 3, respectively, and that the equations of $r_{\mathrm{F}}(l)=0$ and $r_{\mathrm{R}}(l)=0$ exclude Path 2 and Path 4, respectively. Model $A_{R}$ is represented by Eq. (2) in which $q$ is reduced in Eq. (1). The upper left terminus of the $U$-shaped retention ratio $\phi(l)$ becomes 1 (Fig. 4; Model A, $0<p<1, q=1$ ).

$\phi_{1}(l)=(1-p)+p r_{\mathrm{F}}(l)+p\left[1-r_{\mathrm{F}}(l)\right]\left[1-r_{\mathrm{R}}(l)\right]$

Model $A_{R}$ includes the four other paths and not Path 3 because the contact probability of the RP, $q=1$ means that all fish passing through the FP come in contact with the RP.

Model $\mathrm{A}_{\mathrm{F}}$ is represented by Eq. (3) in which $p=1$ in Eq. (1) (Fig. 4; Model A, $p=1,0<q<1$ ).

$\phi_{2}(l)=r_{\mathrm{F}}(l)+q\left[1-r_{\mathrm{F}}(l)\right]\left[1-r_{\mathrm{R}}(l)\right]$

Model $A_{F}$ includes all of the other four paths and not Path 1 since the contact probability against the FP, $p=1$, suggests that all fish come in contact with the FP.
Model $\mathrm{A}_{\mathrm{FR}}$ is represented by Eq. (4) in which both of $p$ and $q$ are equal to 1 in Eq. (1) (Fig. 4; Model A, $p=1$, $q=1$ ). This suggests that Model $\mathrm{A}_{\mathrm{FR}}$ has neither Path 1 nor Path 3.

$\phi_{3}(l)=r_{\mathrm{F}}(l)+\left[1-r_{\mathrm{F}}(l)\right]\left[1-r_{\mathrm{R}}(l)\right]$

In Model $\mathrm{B}$, the proportion $\phi_{l}$ showed a monotonically decreasing sigmoidal function when $r_{\mathrm{F}}(l)=0$, suggesting that all of the fish entering the net were of a body size too small to be retained by the mesh of the FP (Fig. 4). Model $\mathrm{B}$ is based on $p, q$, and $r_{\mathrm{R}}(l)$ as represented by Eq. (5) (Fig. 4; Model B, $0<p<1,0<q<1$ ).

$\phi_{4}(l)=(1-p)+p q\left[1-r_{\mathrm{R}}(l)\right]$

In Model B groups, $r_{\mathrm{F}}(l)=0$ indicates no Path 2 because all fish coming in contact with the FP can pass through the FP.

Model $\mathrm{B}_{\mathrm{R}}$ is represented by Eq. (6) in which $q=1$ in Eq. (5) (Fig. 4; Model B, $0<p<1, q=1$ ). This indicates no Path 3 of Path 2 in Model $B_{R}$.

$\phi_{5}(l)=(1-p)+p\left[1-r_{\mathrm{R}}(l)\right]$

Model $\mathrm{B}_{\mathrm{F}}$ is represented by the Eq. (7) in which $p=1$ in Eq. (5) (Fig. 4; Model B, $p=1,0<q<1$ ), which means that both Path 1 and Path 2 are excluded.

$\phi_{6}(l)=q\left[1-r_{\mathrm{R}}(l)\right]$

Model $\mathrm{B}_{\mathrm{FR}}$ is represented by Eq. (8) in which both $p$ and $q$ are 1 in Eq. (5) (Fig. 4; Model B, $p=1, q=1$ ).

$\phi_{7}(l)=1-r_{\mathrm{R}}(l)$

In Model $\mathrm{B}_{\mathrm{FR}}$, both Path 1 and Path 3 are excluded because of $q=1$ and $p=1$, as well as Path 2 .

Model $\mathrm{C}_{\mathrm{F}}$ is composed of $r_{\mathrm{F}}(l)$ and $p$ in Eq. (9) when $r_{\mathrm{R}}(l)=1$, meaning that all of the fish, even those passing 
Model A

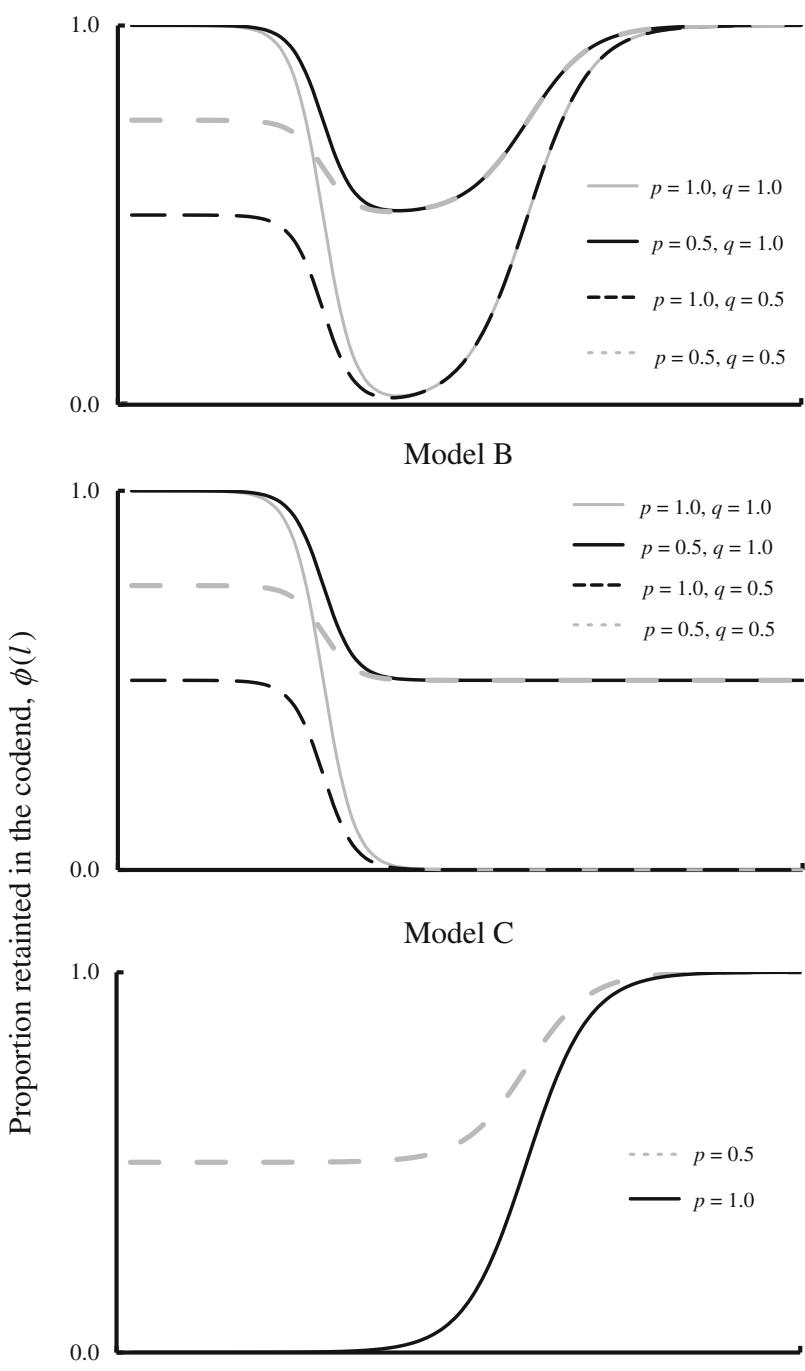

Model D

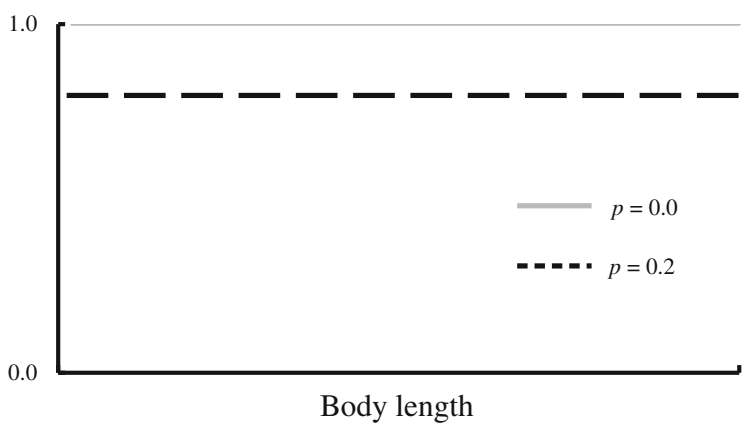

Fig. 4 Curves of the models for expressing the proportion of catch retained in the cod-end

through the FP, were too large to pass through the mesh of the RP, and/or when $q=0$; that is, none of the fish passing the FP came in contact with the RP (Fig. 4; Model C, $0<p<1)$. The former $\left[r_{\mathrm{R}}(l)=1\right]$ excludes Path 5 , and the later means the exclusion of Path 3 with Paths 1 and 2.

The proportion $\phi_{l}$ is sigmoidal.

$\phi_{8}(l)=(1-p)+p r_{\mathrm{F}}(l)$

Model $\mathrm{C}_{\mathrm{R}}$ is represented by Eq. (10) in which $p$ is 1 in Eq. (9) (Fig. 4; Model C, $p=1$ ). This suggests that Path 1 is also excluded in Model $\mathrm{C}_{\mathrm{F}}$.

$\phi_{9}(l)=r_{\mathrm{F}}(l)$

In Model $\mathrm{D}, \phi_{l}$ is constant. There appears to be no size selection by body size for fish that enter the trawl (Fig. 4; Model $\mathrm{D}, 0<p<1)$.

$\phi_{10}(l)=1-p$

This would occur after some portion of the fish come in contact with the FP $(p \neq 0)$, when $r_{\mathrm{F}}(l)=0$ and $q=0$ (meaning Paths 1 and 3), or when $r_{\mathrm{F}}(l)=0$ and $r_{\mathrm{R}}(l)=1$ (excluding Paths 2 and 5), implying that all of the fish passing through the FP escape through the side-vent without coming into contact with the RP or after being retained by the RP. Likewise, two formulas, $1-p+p q$ (when $p$ and $q$ both $\neq 0$ ) and $q$ (when $p=1$, excluding Path 1), are derived under the condition of $r_{\mathrm{F}}(l)=0$ and $r_{\mathrm{R}}(l)=1 \quad$ (excluding Paths 2 and 5), but are indistinguishable from Eq. (11) in terms of parameter estimation.

Model $\mathrm{D}_{\mathrm{F}}$ is represented by Eq. (12) when $p=0$ or when $r_{\mathrm{F}}(l), r_{\mathrm{R}}(l)=0$ at any $p$ value (Fig. 4; Model D, $p=0$ or $\left.r_{\mathrm{F}}(l)=0\right)$, meaning Path 1 expressing that all fish avoid coming in contact with the FP, or excluding Path 4 .

$\phi_{10}(l)=1$

This equation describes the case in which all of the fish passing through the FP also pass through the RP without moving through the side-vent $\left(q=1\right.$ and $r_{\mathrm{R}}(l)=0$, excluding Paths 3 and 4).

In this study, the model that produced a selectivity curve most closely resembling the plots of $\phi_{l}$ in the catch data was selected from among the proposed models by the Akaike Information Criterion (AIC) model selection [20, 21]. The two parameters $p$ and $q$ of contact probability and two sets of logistic function parameters $\left(a_{\mathrm{F}}, b_{\mathrm{F}}\right)$ and $\left(a_{\mathrm{R}}\right.$, $b_{\mathrm{R}}$ ), representing the contact selectivities for the FP and $\mathrm{RP}$, respectively, in the model were estimated using the maximum likelihood method [22]. Here, $N_{l k}$ denotes the total number of fish caught by body length class $l_{k}(k=1$, $2,3, \ldots, n)$, and $C_{l k}$ is the number of fish of body length $l_{k}$ caught in the cod-end. The function $\phi\left(l_{k}\right)$ expresses the proportion of the cod-end catch number $C_{l k}$ to the total number of fish $N_{l k}$. The log likelihood function to be maximized for parameter estimation is as follows: 


$$
\begin{aligned}
\ln L\left(p, a_{F}, b_{F}, q, a_{R}, b_{R}\right)= & \sum_{k}^{n} \ln \frac{C_{K} !}{\left(N_{K}-C_{K}\right) ! \cdot C_{K} !} \\
& +\sum_{k}^{n} C_{k} \ln \phi\left(l_{k}\right) \\
& +\sum_{k}^{n}\left(N_{k}-C_{k}\right) \ln \left[1-\phi\left(l_{k}\right)\right]
\end{aligned}
$$

The Solver function in Microsoft Excel (Microsoft, Redwood, WA) was used to maximize the log likelihood function [22]. Model fitness was tested by the likelihood ratio test on data in length classes, with sample numbers of at least five, in the same fashion as proposed by Miller and Walsh [23].

\section{Results}

Height of net mouth, BRD and catch composition

Mean height of net mouth ranged from 2.2 to $3.1 \mathrm{~m}$ for the prototype, and from 4.1 to $4.5 \mathrm{~m}$ for the improved type (Table 1). The mean height of the BRD ranged from 1.6 to $1.8 \mathrm{~m}$ for the improved type. Apart from haul No. 5 with a BRD height of about $0.1 \mathrm{~m}$ for the prototype, the mean height of the BRD was maintained from 0.4 to $0.8 \mathrm{~m}$. Since the low height of BRD in haul No. 5 implied less effect of FP and RP contact selection, data in haul No. 5 were excluded from further analyses.

Catch composition by catch number and weight for the prototype and improved type used in the fishing experiments is shown in Table 2. The top ten and 11 most abundant fish species caught in the after-sunset trawls using the prototype and improved type are listed in Tables 3 and
4, respectively. Little difference in catch composition was observed between the two types. For example, the portunid swimming crab Portunus hastatoides was dominant in the catch with the improved type, but not so in the catch with the prototype. In contrast, although offshore pony Leiognathus rivulatus appeared in the top ten species caught by the prototype, but there were no appearances in the list of the top 11 species caught by the improved type. The first four hauls using the prototype were conducted in July and the other six (Haul No. 5-10) were conducted in September, while the hauls using the improved type took place in June (Table 1). Possible explanations for differences in catch composition are differences in towing season and/or in towing ground. Regardless of season or location, the most common and second most common species caught by both the prototype and improved type were whiskered velvet shrimp and spotted swimming crab. Whiskered velvet shrimp accounted for 39 and $28 \%$ and spotted swimming crab for 17 and $26 \%$ of the individuals caught by the prototype and improved type, respectively. For the prototype and the improved type, the most common marketable fish species were cinnamon flounder and lizard fish, and catch numbers for these species were sufficient for conducting analysis on available selection provided by the BRD. In this study, catch data for the four species (whiskered velvet shrimp, spotted swimming crab, lizard fish, and cinnamon flounder) were used for further analysis on available selection.

Body length composition and estimated model curves of available selection

Body length composition of the four species was obtained from the catch data pooled in all hauls for the prototype and improved type, respectively (Fig. 5). The models in
Table 1 Towing conditions in the fishing experiments by beam trawl with the prototype and improved type of SURF-BRD
SURF-BRD, System of Unwants Ramp-way FilteredBycatch Reduction Device

\begin{tabular}{llllll}
\hline BRD type & Haul number & Date of tow & Towing time & $\begin{array}{l}\text { Height of } \\
\text { BRD }(\mathrm{m})\end{array}$ & $\begin{array}{l}\text { Height of net } \\
\text { mouth }(\mathrm{m})\end{array}$ \\
\hline Prototype & 1 & 1 July 1996 & $19: 51-20: 41$ & 0.31 & 2.50 \\
& 2 & 8 September 1998 & $19: 05-19: 55$ & 0.13 & 2.18 \\
& 3 & & $20: 10-21: 12$ & 0.45 & 2.47 \\
& 4 & & $21: 32-22: 35$ & 0.67 & 2.98 \\
& 5 & & $22: 52-23: 52$ & 0.61 & 2.92 \\
Improved type & 1 & 10 September 1998 & $19: 21-20: 23$ & 0.69 & 3.11 \\
& 6 & & $20: 40-21: 42$ & 0.80 & 3.17 \\
& 2 & 29 June 2000 & $19: 33-20: 30$ & 1.72 & 4.17 \\
& 3 & & $20: 50-21: 50$ & 1.78 & 4.34 \\
& 4 & & $22: 11-23: 11$ & 1.78 & 4.09 \\
& 5 & & $23: 30-00: 31$ & 1.55 & 4.06 \\
& 6 & 30 June 2000 & $19: 30-20: 30$ & 1.91 & 4.52 \\
\hline
\end{tabular}


Table 2 Catch number and weight in the fishing experiment

\begin{tabular}{|c|c|c|c|c|c|c|c|c|c|c|c|}
\hline \multirow{2}{*}{$\begin{array}{l}\text { Type of } \\
\text { BRD }\end{array}$} & \multirow[t]{2}{*}{ Bag } & \multicolumn{2}{|l|}{ Fish } & \multicolumn{2}{|l|}{ Crustacea } & \multicolumn{2}{|c|}{ Cephalopoda } & \multicolumn{2}{|l|}{ Others } & \multicolumn{2}{|l|}{ Total } \\
\hline & & Number & $\begin{array}{l}\text { Weight } \\
(\mathrm{kg})\end{array}$ & Number & $\begin{array}{l}\text { Weight } \\
(\mathrm{kg})\end{array}$ & Number & $\begin{array}{l}\text { Weight } \\
(\mathrm{kg})\end{array}$ & Number & $\begin{array}{l}\text { Weight } \\
(\mathrm{kg})\end{array}$ & Number & $\begin{array}{l}\text { Weight } \\
(\mathrm{kg})\end{array}$ \\
\hline \multirow[t]{3}{*}{ Prototype } & Cod-end & 1,355 & 21.82 & 4,372 & 19.53 & 167 & 5.74 & 19 & 0.49 & 5,913 & 47.58 \\
\hline & Side-vent cover & 201 & 2.18 & 1,226 & 6.38 & 25 & 0.34 & 13 & 0.22 & 1,465 & 9.13 \\
\hline & Total & 1,556 & 24.01 & 5,598 & 25.91 & 192 & 6.08 & 32 & 0.71 & 7,378 & 56.71 \\
\hline \multirow[t]{3}{*}{ Improved type } & Cod-end & 941 & 20.52 & 9,799 & 33.88 & 36 & 4.80 & 4 & 0.05 & 10,780 & 59.24 \\
\hline & Side-vent cover & 471 & 4.99 & 11,650 & 50.78 & 12 & 0.52 & 25 & 0.30 & 12,158 & 56.59 \\
\hline & Total & 1,412 & 25.51 & 21,449 & 84.65 & 48 & 5.32 & 29 & 0.35 & 22,938 & 115.83 \\
\hline Total & & 2,968 & 49.51 & 27,047 & 110.56 & 240 & 11.40 & 61 & 1.06 & 30,316 & 172.54 \\
\hline
\end{tabular}

Table 3 Top ten species based on size of catch by the beam trawl with prototype of SURFBRD

Table 4 Top 11 species based on size of catch by the beam trawl with improved type of SURF-BRD

\begin{tabular}{llcc}
\hline English name & Species name & Catch $(n)$ & Percentage \\
\hline Whiskered velvet shrimp & Metapenaeopsis barbata & 3,165 & 39.2 \\
Spotted swimming crab & Charybdis bimaculata & 1,341 & 16.6 \\
Tora velvet shrimp & Metapenaeopsis acclivis & 474 & 5.9 \\
Southern rough shrimp & Trachypenaeus curvirostris & 312 & 3.9 \\
Offshore ponyfish & Leiognathus rivulatus & 311 & 3.9 \\
Lizard fish & Saurida spp. & 231 & 2.9 \\
Blunt-toothed crab & Charybdis truncata & 220 & 2.7 \\
Vertical striped cardinalfish & Apogon lineatus & 147 & 1.8 \\
Cinnamon flounder & Pseudorhombus cinnamoneus & 126 & 1.6 \\
Halfline cardinalfish & Apogon semilineatus & 113 & 1.4 \\
Others & Others & 2,918 & 20.2 \\
Total & & 9,358 & 100.0 \\
\hline
\end{tabular}

\begin{tabular}{llcc}
\hline English name & Species name & Catch size $(n)$ & Percentage \\
\hline Whiskered velvet shrimp & Metapenaeopsis barbata & 8,170 & 28.2 \\
Spotted swimming crab & Charybdis bimaculata & 7,653 & 26.4 \\
Blunt-toothed crab & Charybdis truncata & 2,341 & 8.1 \\
Portunid swimming crab & Portunus hastatoides & 1,595 & 5.5 \\
Tora velvet shrimp & Metapenaeopsis acclivis & 477 & 1.6 \\
Vertical striped cardinalfish & Apogon lineatus & 414 & 1.4 \\
Cinnamon flounder & Pseudorhombus cinnamoneus & 173 & 0.6 \\
Golden cusk & Sirembo imberbis & 164 & 0.6 \\
Chinese mud shrimp & Solenocera koelbeli & 156 & 0.5 \\
Southern rough shrimp & Trachypenaeus curvirostris & 115 & 0.4 \\
Lizard fish & Saurida spp. & 80 & 0.3 \\
Others & Others & 2,388 & 26.3 \\
Total & & 23,726 & 100.0 \\
\hline
\end{tabular}

which the parameters converged were limited (Table 5). For cinnamon flounder, the parameters were successfully estimated in seven and six models (except Model C) from data collected with the prototype and the improved type, respectively (Table 5). The model parameters of spotted swimming crab were estimated in all models except Model $\mathrm{C}_{\mathrm{F}}$ for the prototype and in all models for the improved type except Model B of monotonic decrease and Models $\mathrm{A}_{\mathrm{F}}$ and $\mathrm{A}_{\mathrm{FR}}$, assuming that all spotted swimming crabs contacted the FP $(p=1)$. There was no convergence in 
Fig. 5 Length distributions of the four species
Prototype

Improved type
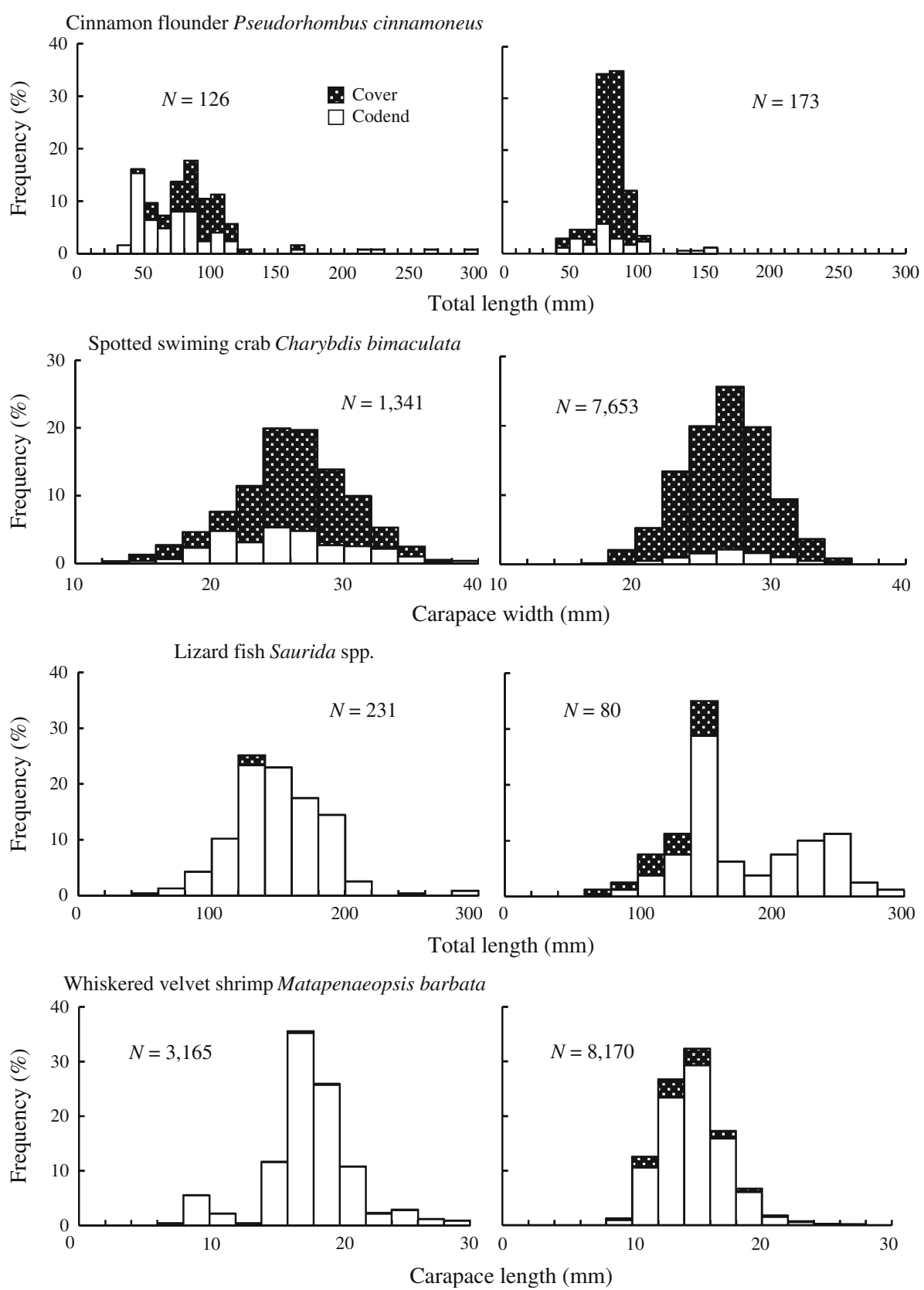

Model B in the monotonic decrease for lizard fish. Parameter estimation was successful only for Model D for whiskered velvet shrimp. Of the models in which the parameters converged in the maximum likelihood analysis for the four species, the AIC values are also shown in Table 5. The observed proportion of fish retained in the cod-end, $\phi_{l}$ was plotted against body length with the estimated $\phi(l)$ curve of the model selected as the model with the best fit by the AIC (Fig. 6). The estimated parameters of contact probability and the contact selection curve for the FP and RP estimated for these four species are shown in Table 6.

Cinnamon flounder

The mode in TL distribution of the cinnamon flounder caught in the cod-end and cover was from 80 to $90 \mathrm{~mm}$ for both the prototype and improved type (Fig. 5). While the TL range was from 30 to $300 \mathrm{~mm}$ for the prototype and from 40 to $160 \mathrm{~mm}$ for the improved type, the TL range 
Table 5 Akaike information criterion values of each model for the four species

\begin{tabular}{|c|c|c|c|c|c|c|c|c|}
\hline \multirow[t]{2}{*}{ Model $^{\mathrm{a}}$} & \multicolumn{2}{|c|}{$\begin{array}{l}\text { Cinnamon flounder } \\
\text { Pseudorhombus cinnamoneus }\end{array}$} & \multicolumn{2}{|c|}{$\begin{array}{l}\text { Spotted swimming crab } \\
\text { Charybdis bimaculata }\end{array}$} & \multicolumn{2}{|c|}{ Lizard fish Saurida spp. } & \multicolumn{2}{|c|}{$\begin{array}{l}\text { Whiskered velvet shrimp } \\
\text { Matapenaeopsis barbata }\end{array}$} \\
\hline & Prototype & Improved type & Prototype & Improved type & Prototype & Improved type & Prototype & Improved type \\
\hline A & 39.7 & 32.9 & $108.0^{\mathrm{b}}$ & 76.9 & 26.0 & - & - & - \\
\hline$A_{R}$ & $37.7^{\mathrm{a}}$ & 32.0 & 114.9 & 74.9 & 37.7 & - & - & - \\
\hline$A_{F}$ & 40.3 & - & 114.9 & - & - & - & - & - \\
\hline$A_{F R}$ & 40.0 & $30.0^{\mathrm{b}}$ & 112.9 & - & - & - & - & - \\
\hline B & 45.8 & 57.9 & 119.4 & - & - & - & - & - \\
\hline $\mathrm{B}_{\mathrm{R}}$ & 43.7 & 56.7 & 147.1 & - & - & - & - & - \\
\hline $\mathrm{B}_{\mathrm{F}}$ & - & - & 247.9 & - & - & - & - & - \\
\hline $\mathrm{B}_{\mathrm{FR}}$ & - & 70.3 & 245.9 & - & - & - & - & - \\
\hline $\mathrm{C}$ & - & - & 137.8 & $71.1^{\mathrm{b}}$ & $20.5^{\mathrm{b}}$ & 21.5 & - & - \\
\hline $\mathrm{C}_{\mathrm{F}}$ & - & - & - & 94.8 & - & $15.5^{\mathrm{b}}$ & - & - \\
\hline $\mathrm{D}$ & 63.1 & - & 166.5 & 97.6 & 24.3 & 33.8 & $53.9^{\mathrm{b}}$ & $114.6^{\mathrm{b}}$ \\
\hline
\end{tabular}

-, Not converged

" For a detailed description of the models, see section "Numerical models used for data analysis"

${ }^{\mathrm{b}}$ Best fitted model with the smallest Akaike information criterion (AIC)

within which five or more individuals were caught by the prototype and improved type was from 40 to $120 \mathrm{~mm}$ and from 40 to $110 \mathrm{~mm}$, respectively (Fig. 5). For the prototype, the $\phi_{l}$ values decreased from 1 to about 0.3 within the TL range from 40 to $120 \mathrm{~mm}$. In contrast, for the improved type, the $\phi_{l}$ values decreased from approximately 0.6 to 0.1 within the TL range from 50 to $90 \mathrm{~mm}$, and then increased to 0.67 at the $100-$ to $110-\mathrm{mm}$ TL class (Fig. 6a). In the $>200-\mathrm{mm}$ TL class for the prototype and the 130- to $150-\mathrm{mm}$ TL class for the improved type, the $\phi_{l}=1$, although the catch numbers were less than five. Thus, the plots of $\phi_{l}$ values versus TL were a $U$-shaped curve in the two SURF-BRD types for this species (Fig. 6a). In fact, of the Model $\mathrm{A}$ groups that have $U$ shaped curves, those in Model $A_{R}$ and Model $A_{F R}$ were selected by the AIC model selection as the best fit for the prototype and improved types, respectively (Table 5). The results of the model selection suggested that the contact probability was 1 for fish against the RP in the prototype and 1 for fish against FP and RP in the improved type. The estimated probability of this species coming in contact with the FP was 0.70 for the prototype. The likelihood ratio tests $[12,23]$ showed that there was no lack of goodness-of-fit $(p>0.05)$, nor was there systematic bias in the deviance residuals versus TL (Fig. 6a). There was a difference in the $50 \%$ selection length of the FP between the two types (172 $\mathrm{mm}$ for the prototype vs. $107.6 \mathrm{~mm}$ for the improved type), which was probably due to having too small sample numbers within the TL range relative to the FP size selection for the two types of BRD (Fig. 6a). On the other hand, no large difference was found in the $50 \%$ selection length of RP (69.4 vs. $53.3 \mathrm{~mm}$ in TL) between the two types (Table 6).

Spotted swimming crab

Five or more individuals for the spotted swimming crab were caught within the $\mathrm{CW}$ range from 12 to $40 \mathrm{~mm}$ for the prototype and from 16 to $36 \mathrm{~mm}$ for the improved type (Fig. 6b). Apart from the two CW classes of 18-20 and 20$22 \mathrm{~mm}$, the $\phi_{l}$ value for the spotted swimming crab caught by the prototype were around 0.25 , fluctuating for $\mathrm{CW}$ between 14 to $32 \mathrm{~mm}$ and increasing for $\mathrm{CW}$ over $32 \mathrm{~mm}$ to 1 in the 38 to $40 \mathrm{~mm} \mathrm{CW}$ class. In contrast, the $\phi_{l}$ for this species for the improved type appeared to be constant within the $\mathrm{CW}$ range from 18 to $30 \mathrm{~mm}$. Model A was the most complicated one selected for the prototype by the AIC comparison (Table 5). However, the likelihood ratio test showed a lack of fit (Table 6), and values over 2 in deviance residual were found for four of the $\mathrm{CW}$ classes: $12-14,16-18,20-22,38-40 \mathrm{~mm}$. In contrast, Model C was the best fitted for the improved type without any lack of fitness in the likelihood ratio test $(P>0.05)$ and any systematic bias in deviance residual versus CW (Fig. 6b). This suggests that there is no effective size selection of the RP within the $\mathrm{CW}$ range of this species. The estimated contact probability of the FP was 0.92 (Table 6), which means that $8 \%$ of the spotted swimming crab encountering the net mouth entered the cod-end through Path 1 without coming in contact with the FP. The values of $l_{50}$ for the FP were 


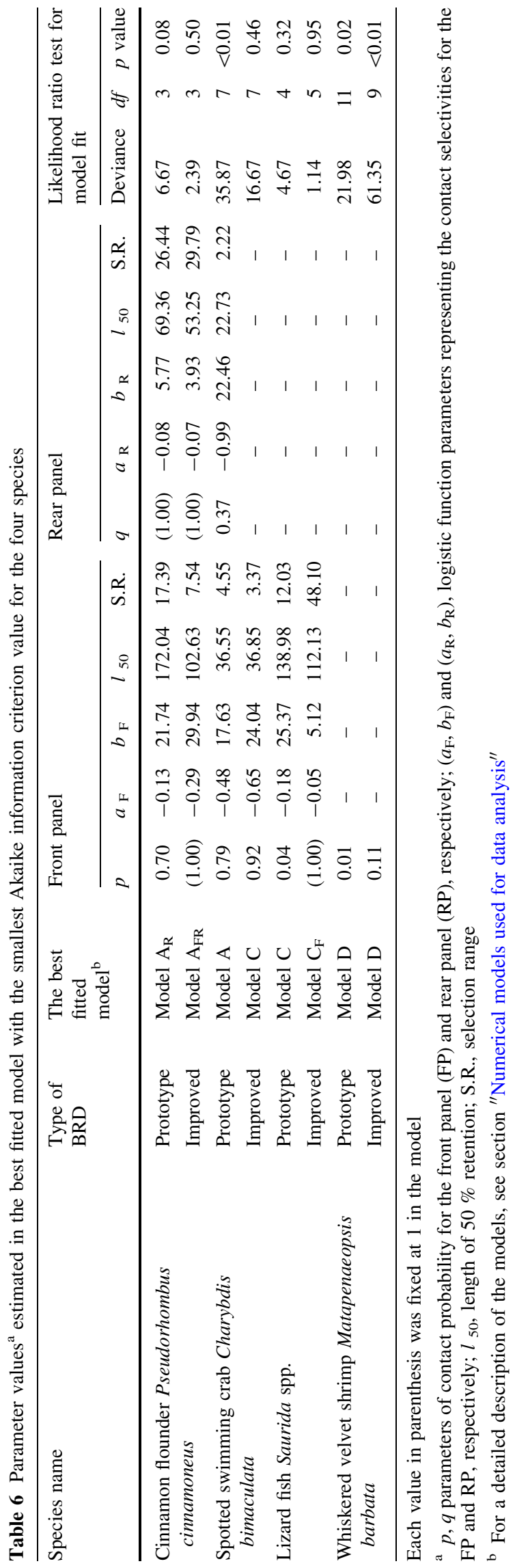

Fig. 6 a Proportion of cinnamon flounder Pseudorhombus cinnamoneus retained in the cod-end with curves of the fitted model and deviance residuals, $\mathbf{b}$ proportion of spotted swimming crab Charybdis bimaculata retained in the cod-end with curves of the fitted models and deviance residuals, c proportion of lizard fish Saurida spp. retained in the cod-end with curve of the fitted model and deviance residuals, $\mathbf{d}$ proportion of whiskered velvet shrimp Matapenaeopsis barbata retained in the cod-end with curves of the fitted models and deviance residuals. a-d Long and short broken lines Selection curve of FP and RP, respectively, AIC Akaike information criterion, with the smallest AIC indicating the best fitted model, $p$ probability in likelihood ratio test for model fit

very close between the two types; $37.6 \mathrm{~mm}$ for the prototype and $36.9 \mathrm{~mm}$ for the improved type.

\section{Lizard fish}

The range of the TL for lizard fish was from 40 to $300 \mathrm{~mm}$ for the prototype and from 60 to $300 \mathrm{~mm}$ for the improved type (Fig. 6c). For the prototype, $\phi_{l}=1$, except for 0.93 for the 120- to 140-mm TL class. On the other hand, the $\phi_{l}$ values for the improved type showed a sigmoidal increase from 0.5 to 1.0 , with increasing TL from 60 to $180 \mathrm{~mm}$, and these were constant at 1.00 for TL $>180 \mathrm{~mm}$ (Fig. 6c). The AIC model selected Model $\mathrm{C}$ for the prototype and Model $\mathrm{C}_{\mathrm{F}}$ for the improved type (Table 5). There was no lack of fitness by the likelihood ratio test $(p>0.10$; Table 6). The FP contact probability for this species was estimated to be 0.04 for the prototype (Table 6), while all of the lizard fish encountering the net mouth came in contact with the FP in the improved type, as suggested by Model $\mathrm{C}_{\mathrm{F}}$ selected by the AIC. The $50 \%$ selection length of the FP for this species was $139 \mathrm{~mm}$ for the prototype and $112 \mathrm{~mm}$ for the improved type.

Whiskered velvet shrimp

The CL of the whiskered velvet shrimp ranged from 6 to $30 \mathrm{~mm}$ for the prototype and from 8 to $28 \mathrm{~mm}$ for the improved type, and sample sizes seemed to be sufficient for analysis at these CL length classes (Fig. 5). The $\phi_{l}$ values for this species for the prototype were almost 1 ( 0.92 1.00), while those for the improved type were slightly smaller, ranging from 0.76 to 0.92 (Fig. 6d). Even though Model D was selected by the AIC model selection for both the prototype and the improved type (Table 5), likelihood ratio testing indicated a lack of model fitness (Table 6). Much worse, deviance residuals of $>2$ were found for several CL classes for both types (Fig. 6d). The plots of $\phi_{l}$ values against $\mathrm{CL}$ showed a convex upward curve for the improved type, which was definitely distinct from the other curves proposed in this study (Fig. 4). Still, the value of parameter $p$ estimated by Model D was 0.01 for the prototype and 0.11 for the improved type. This implies that 
(a)
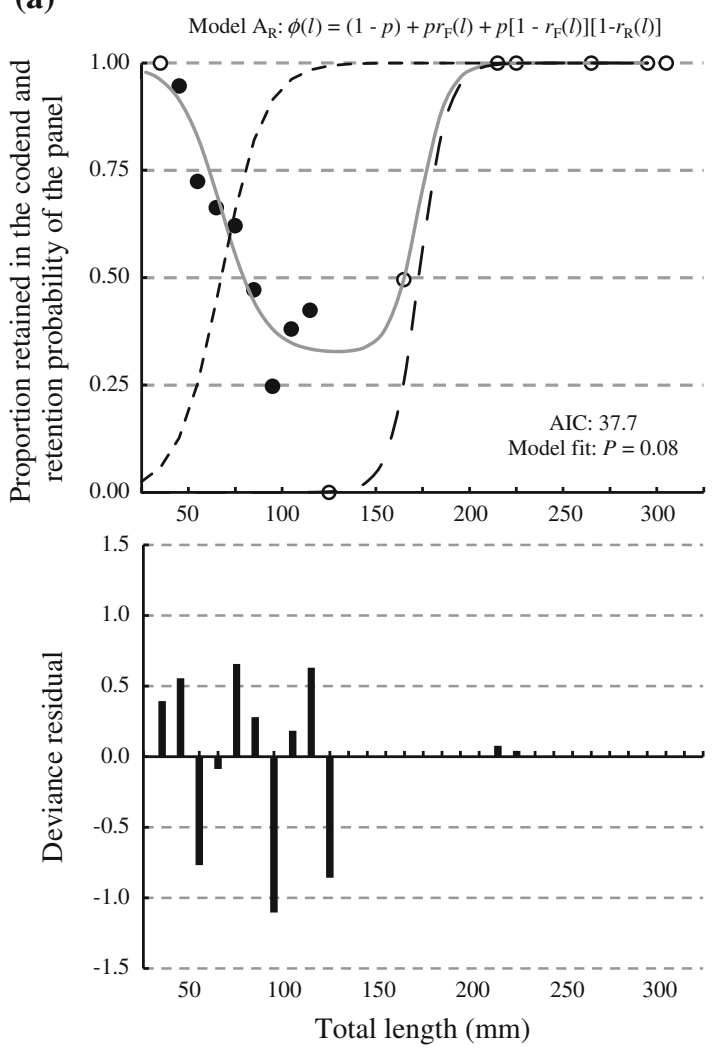

(b)
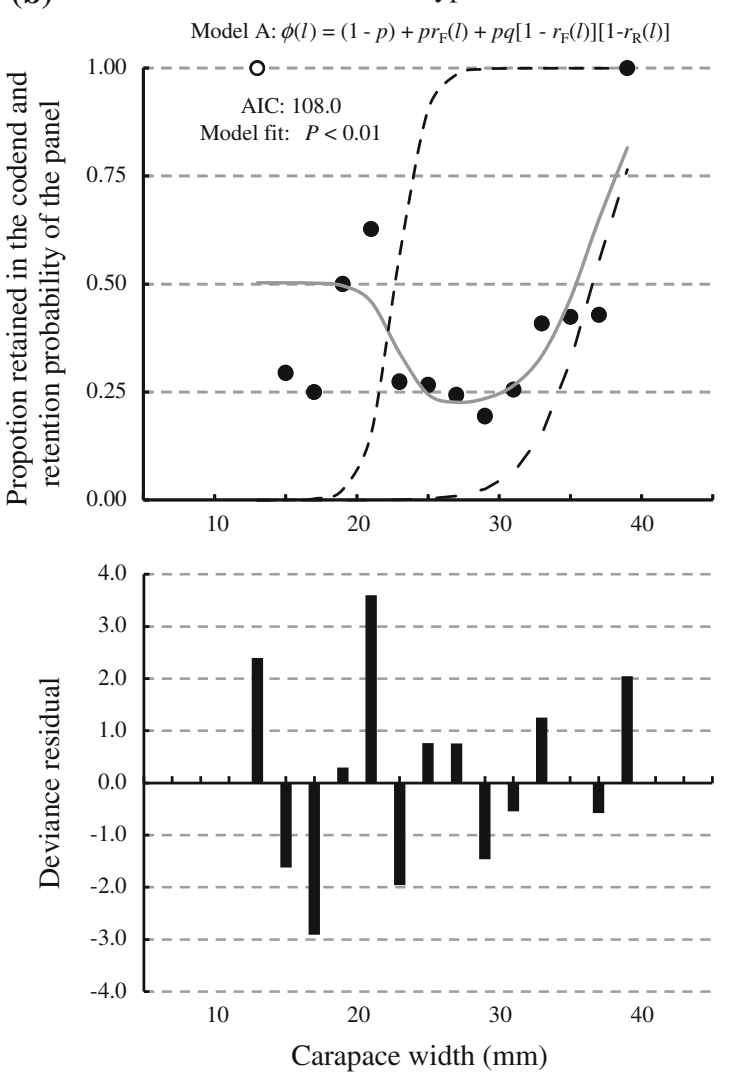

Improved type
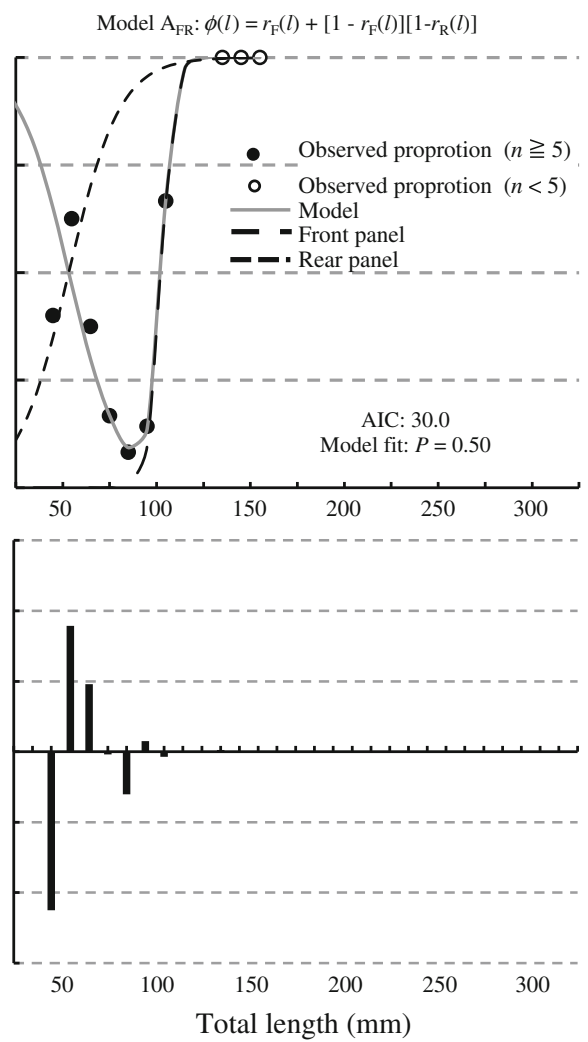

Improved type

Model C: $\phi(l)=(1-p)+p r_{\mathrm{F}}(l)$
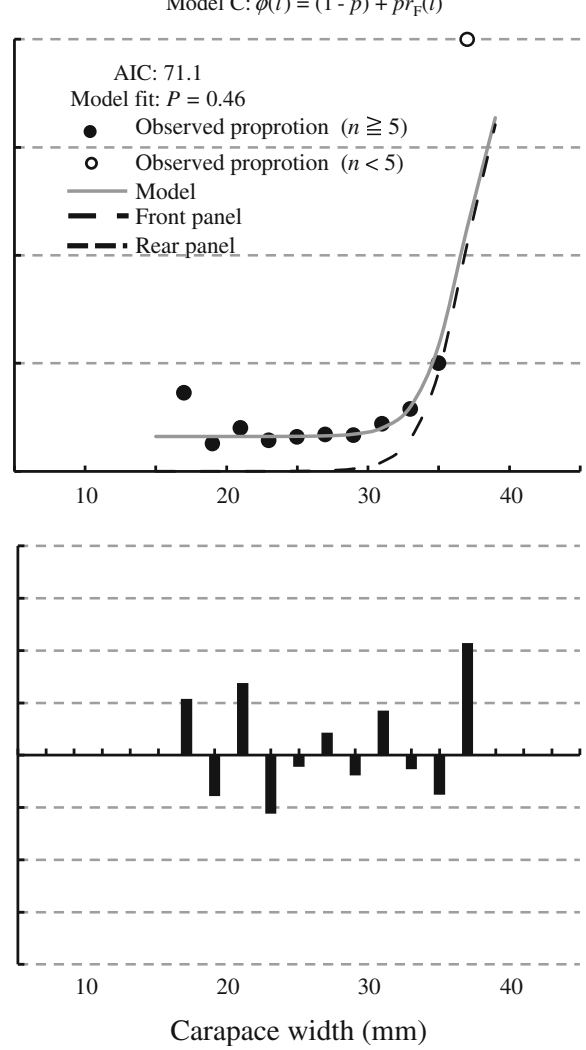

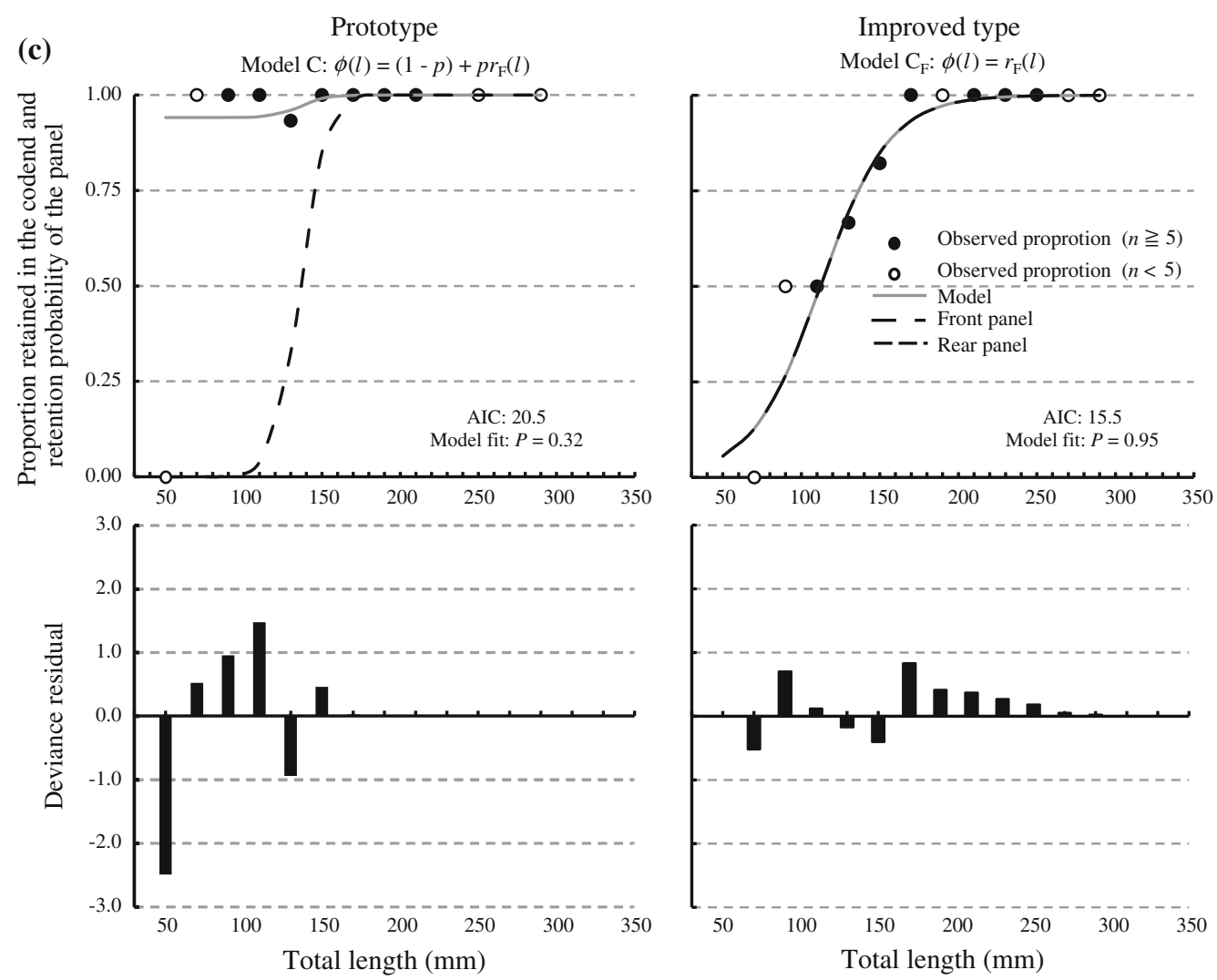

(d)

Prototype

Improved type

Model D: $\phi(l)=1-p$

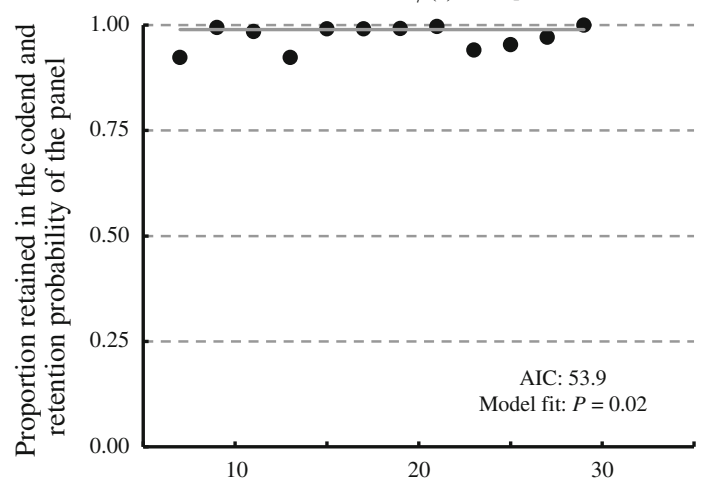

Model D: $\phi(l)=1-p$
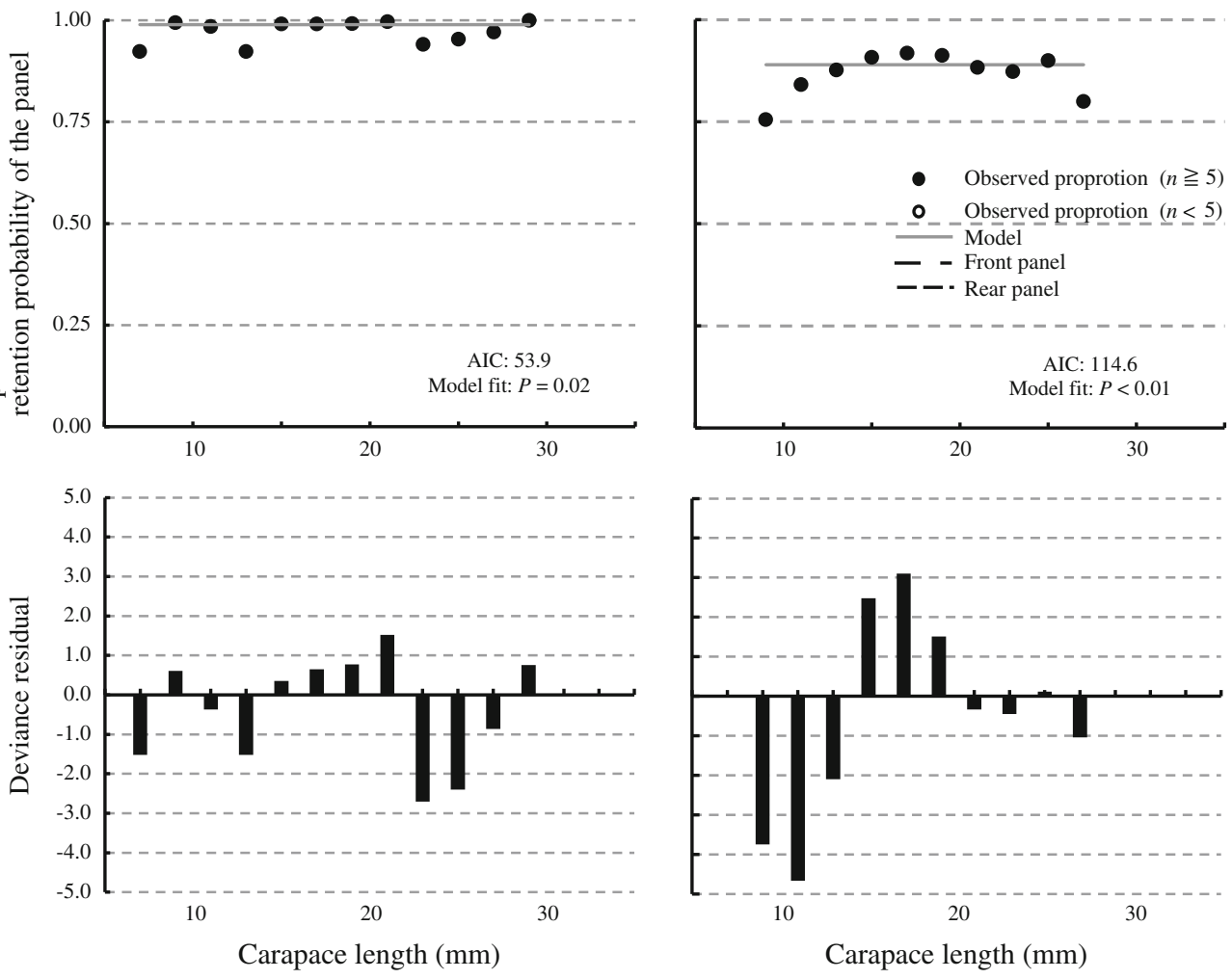

Fig. 6 continued 
almost all of the whiskered velvet shrimp entering the net mouth were retained in the cod-end of the prototype and that only small numbers of this species pass through the FP and escaped through the side vent.

\section{Discussion}

Validity of models describing the selection process for the SURF-BRD

In this study, the parameters describing size selection of the FP were estimated for three species: cinnamon flounder, spotted swimming crab, and lizard fish (Table 6). Size selection parameters of the RP were obtained for cinnamon flounder and spotted swimming crab. It is well accepted that mesh size is one of the most important factors in size selection of the trawl cod-end. Here, to examine the validity of the model proposed in this study, we compared the estimated size selection parameters of the FP and RP with previously reported size selection parameters of the cod-end. The shape of the mesh of the FP used in the SURF-BRD was square. It is also well accepted that for round-bodied fish a cod-end with a square mesh has a higher $50 \%$ retention length $\left(L_{50}\right)$ than a cod-end with a diamond mesh [24], whereas for plaice the opposite is true [25]. He [26] recently reported that mesh shape (diamond or square) has no significant effect on the $L_{50}$ for roundbodied fish while square mesh cod-ends have significantly smaller $L_{50}$ for flounders. For the two fishes and the two crustaceans evaluated in this study, the mesh selectivity of a square mesh cod-end is still unknown; therefore, we compared our results with the mesh selectivity of diamond mesh cod-ends reported in a number of previous reports.

The $L_{50}$ of the FP for cinnamon flounder was estimated to be $102 \mathrm{~mm}$ in TL in the improved type, apart from that estimated from data of small sample size in the prototype (Table 6). From data on body size measurement of cinnamon flounder sampled in the fishing experiment, the relationship between TL $l$ and body height $l_{\mathrm{D}}$ was estimated by the following equation;

$l_{\mathrm{D}}=0.42 l-2.32$ (coefficient of determination, $R^{2}=0.98$;

$$
n=28 \text { ) }
$$

With this equation, the body height corresponding to the TL of $50 \%$ selection was calculated to be $41 \mathrm{~mm}$, and the selection factor in terms of body height $(50 \%$ body height/ stretched mesh size: $l_{\mathrm{D}} / m$ ) was 0.566 . Tokai [27] reported that the retention probability of the cod-end mesh ranged from 0 to 1 as the ratio of body height $l_{\mathrm{D}}$ to mesh size $m$ increased from approximately 0.5 to 1.0 with a diamond mesh and a target catch of ridged-eye flounder Pleuronichthys cornutus and marbled flounder
Pseudopleuronectes yokohamae, suggesting that flatfish with a body height larger than the mesh opening are unable to pass through the mesh. Yamasaki et al. [28] reported a similar result for willowy flounder Tanakius kitaharai in a cod-end made of diamond mesh. The estimated $l_{\mathrm{D}} / m$ of $50 \%$ retention in the FP of the prototype was 0.566 , which is slightly lower than previously reported results [27, 28]. One possible explanation is that it is slightly more difficult for flatfishes to pass through square mesh than through diamond mesh, as has been pointed out in several papers [e.g., 24, 26, 29]. In any case, these results suggest that size selection of the FP for cinnamon flounder was mainly due to the mesh selection.

The $L_{50}$ of the cod-end with 27.5-mm diamond mesh for five spot flounder Pseudorhombus pentophthalmas, which has a body shape similar to that of cinnamon flounder, has been reported to be a TL of $61 \mathrm{~mm} \mathrm{[30],} \mathrm{and} \mathrm{in} \mathrm{our} \mathrm{study}$ this length was close to the $L_{50}$ of the RP (TL $=69 \mathrm{~mm}$ for the prototype and $\mathrm{TL}=53 \mathrm{~mm}$ for the improved type; Table 6). In addition, using Eq. (14), we showed that the $l_{\mathrm{D}} / m$ values of $50 \%$ selection were 0.96 and 0.73 in the prototype and improved types, respectively, which are also close to previously reported results [24, 25]. These results suggest that the size selection of the RP is equivalent to that of the cod-end mesh.

In this study, Model A was selected to describe the available selection of the prototype for the spotted swimming crab, but the statistical test indicated no fitness of the model $(p<0.01)$, while the fitness of the Model $\mathrm{C}$ for the improved type was quite good. The estimated value of $37 \mathrm{~mm}$ as the $50 \%$ selection $\mathrm{CW}$ of the FP for spotted swimming crab in both types (Table 6) was very close to the $39 \mathrm{~mm}$ reported previously as the $50 \%$ retention $\mathrm{CW}$ for diamond mesh cod-end of the same nominal $80-\mathrm{mm}$ mesh size as the FP [31]. On the other hand, the estimated $50 \%$ selection $\mathrm{CW}$ of the RP in the prototype for this species was $22 \mathrm{~mm}$ (Table 6), which is relatively larger than the $13 \mathrm{~mm}$ reported as the $50 \%$ retention $\mathrm{CW}$ in diamond mesh cod-end of the same nominal 27.5-mm mesh size [31]. The $\mathrm{CW}$ range for spotted swimming crab caught in the fishing experiments exceeded $12 \mathrm{~mm}$ for the prototype and $16 \mathrm{~mm}$ for the improved type (Fig. 5), making the sizes too large to estimate the contact selection parameters for the RP of the BRD. This implies that Model $\mathrm{C}$ should have been selected as the better model for the prototype as well as for the improved type.

Liang et al. [32] reported that the $50 \%$ retention TL of Wanieso lizardfish Saurida wanieso in the diamond mesh cod-end with nominal $80-\mathrm{mm}$ mesh size (stretched mesh size $72 \mathrm{~mm}$ ) was $307 \mathrm{~mm}$ TL and also pointed out that round-bodied fish like the lizard fish are likely to pass through a square mesh more easily than through a diamond mesh. In this study, however, the $50 \%$ selection TL of the 
FP for lizards was estimated to be $138 \mathrm{~mm}$ for the prototype and $112 \mathrm{~mm}$ for the improved type (Table 6), which is less than half of the $50 \%$ retention TL of diamond mesh cod-end. The TL of lizard fish caught in the fishing experiments did not exceed $300 \mathrm{~mm}$ (Fig. 5) and, therefore, these could have passed through the FP square mesh based on body size relative to the mesh opening. This results suggests that lizard fish with a larger body size swam up over the BRD without coming in contact with the FP. Generally, larger fish are more likely to have better swimming ability [33]. Thus, we ascribe size selection of the FP for lizard fish to avoidance behavior dependent on fish body size rather than on the contact selection of the FP.

For the whiskered velvet shrimp, as mentioned above in the methods, Model D in which $\phi_{l}$ values were constant against body sizes was selected by the AIC, but no information was provided to distinguish between Path 1 of $1-p$, the Path 5 of $q$, and the Paths 1 and 5 of $(1-p)+p q$. Tora velvet shrimp Metapenaeopsis acclivis, which is a relative species to the whiskered velvet shrimp, has a quite similar body shape. Tokai and Sakaji [34] reported that the retention probability of the $25.1-\mathrm{mm}$ diamond mesh codend for the tora velvet shrimp increased from 0 to 1 with an increase in CL from 10 to $18 \mathrm{~mm}$ and that the $50 \%$ retention CL was about $13.5 \mathrm{~mm}$. The range of CL values of the whiskered velvet shrimp caught in our fishing experiments was from 6 to $30 \mathrm{~mm}$ (Fig. 5). Shrimp of this size would be able to physically pass through the FP square mesh of $80-\mathrm{mm}$ mesh size as its body size is sufficiently smaller than the mesh opening. Moreover, if whiskered velvet shrimp do come into contact with the RP, shrimp with a CL of $>18 \mathrm{~mm}$ would be without question retained by the RP, which has 27.5-mm diamond mesh, and excluded through the side-vent, meaning a low $\phi_{l}$ value for $\mathrm{CL}>18 \mathrm{~mm}$. Shrimp with $\mathrm{CL}<11 \mathrm{~mm}$ would always pass through the RP mesh, which leads to a high $\phi_{l}$ value. These findings suggest that Model A or B should have been selected as the best model when effective mesh selection of the RP is taken into account. However, Model D was selected and there are no indications of good of fitness (Tables 5, 6). A possible explanation is that the whiskered velvet shrimp passing through the FP did not come in contact with the RP and were washed out through the sidevent with the water mass that may be stalled in front of the RP with a fine mesh net. Accordingly, we concluded that all of the whiskered velvet shrimp caught in the cod-end entered the cod-end through Path 1 (Fig. 3).

The height of the improved type was about threefold higher than that of the prototype (Table 1), and the four main species studied here had a higher probability of coming in contact with the FP in the improved type than in the prototype (Table 6). For the lizard fish, the difference in contact probability between the two types was marked.
Of the lizard fish entering the net, most could avoid coming in contact with the FP in the prototype because of their good swimming ability, but all came in contact with the FP in the improved type (Table 6; Fig. 6). In contrast, some portion of the spotted swimming crabs did not come in contact with the FP because the BRD height of the prototype was not as high as that in the improved type for which contact probability was estimated to be 0.92 (Table 6; Fig. 6b). Small shrimps, including the whiskered velvet shrimp, usually burrow into the sea bed during the day and swim some distance away from the sea bed at night [3538]. In our study, we utilized data obtained for night towing when the whiskered velvet shrimp may have been off the sea bed. Consequently, it is possible not as many shrimp as expected came into contact with the FP. This results indicates that both the height of the BRD and the swimming behavior of the animal are the principal factors affecting the probability of animals coming in contact with the FP.

Of the mixed model proposed in this study, although model A was selected as the best one by the AIC model selection process to describe available selection of the prototype for spotted swimming crab, models with a small number of parameters were also run for the other species (Table 5). For the lizard fish, no fish passed through the FP or came in contact with the RP; consequently, the contact selection of this species for the RP could not be estimated. Contact selection parameters were not estimated for species such as the whiskered velvet shrimp not only because the body size ranges were out of the range of the FP and RP contact selection but also because the sample sizes of the body size ranges relevant for estimating model parameters were too small. To express available selection of BRD with sorting panels, such as large mesh panels and grids, the mixed model with contact probability and size selection should be considered, and the appropriate model best fitted to the data should be chosen from the mixed models by some criterion, such as the AIC. When none of the mixed models provide a good fit to the data, the species- and sizeselective process other than the available selection proposed in this study should be considered.

Further improvements in the device based on model evaluations

Cinnamon flounder is a marketable species, and fishermen who trawl off Shimonoseki target members of this species with a TL of $>100 \mathrm{~mm}$ [39]. The TL range of cinnamon flounder caught in the fishing experiments was $30-300 \mathrm{~mm}$ (Fig. 5). In the improved type, all cinnamon flounder entering the net encountered the FP, and thereafter cinnamon flounder of larger sizes were retained by the FP and came into the cod-end through Path 2 , while smaller ones with a TL of approximately $50 \mathrm{~mm}$ entered the cod-end 
after passing through both the FP and the RP — that is, Path 5 (Fig. 6). The FP which has a $50 \%$ selection TL of $107 \mathrm{~mm}$ was partially effective in catching cinnamon flounder with a TL $>100 \mathrm{~mm}$. However, it should be possible to improve the system by switching the RP to a smaller mesh size, which may result in an increased effectiveness in terms of preventing smaller cinnamon flounder from entering the cod-end through Path 5. And, there may still be a possibility for cinnamon flounder to exit through the side-vent without coming into contact with the RP.

The spotted swimming crab is of no commercial value and actually hinders on-deck sorting by fishermen; thus, it should be excluded from the net. Most of the spotted swimming crabs caught in the fishing experiment were $<34 \mathrm{~mm} \mathrm{CW}$ (Fig. 5) and easily passed through the FP. While some spotted swimming crabs were retained in the cod-end of the prototype, the majority of the spotted swimming crabs were successfully excluded in the improved type through the use of an appropriate mesh size for the FP and RP and due to the higher contact probability.

The lizard fish is marketable, as is cinnamon flounder, and the target size has been reported to be $>50 \mathrm{~mm}$ TL [39]. The prototype appeared to have almost no size selection for this species for $\mathrm{TL}>50 \mathrm{~mm}$ (Fig. 5). In contrast, the $50 \%$ selection TL of the FP was $112 \mathrm{~mm}$ in the improved type (Table 6), and thus in order to retain all lizard fish of the target size, a smaller mesh size for the FP would be better. However, the minimum maturity sizes of male and female lizard fish have been reported to be 235 and $249 \mathrm{~mm}$, respectively, for the slender lizard fish Saurida elongate [40] and 180 and $228 \mathrm{~mm}$, respectively, for Saurida umeyoshii [41]. From the point-of-view of fisheries resources management for lizard fishes, the FP mesh size should be greatly enlarged.

Based on the results of this study, we propose mixed models with specific probabilities of animals coming in contact with the sorting panel and size selectivity of the sorting panel to express the available selection of the SURF-BRD, which has the two sorting panels, FP and RP. We estimated the parameters of contact probability and selectivity in the mixed models and then chose the model that best fit the data for each species through the AIC model selection. Appropriate mesh sizes of the sorting panels could be determined based on the estimated available selectivity model. The selectivity parameters of FP and RP in the model were attributed mainly to mesh size selectivity, but for some species also partially to fish swimming ability. Differences in contact probabilities among the species were associated not only with animal behavior but also with the dimension and configuration of the BRD. The mixed models and the model selection process are useful for evaluating the selective processes of the BRD with a sorting panel, such as mesh windows, grids, among others. These models, therefore, are also useful for understanding species- and size-selectivity of the BRD with the sorting panel.

Acknowledgments We would like to thank Drs. Akio Fujiishi and Yoshiki Matsushita for their helpful comments and suggestions, and Drs. Tatsuo Hamano and Ken-Ichi Hayashi for their help in species identification of crustaceans. We also thank Captain Namio Nakatani of the Daisan-kaikomaru for his cooperation in the fishing experiments. Thanks are due to the editor and two anonymous reviewers for providing helpful comments.

Open Access This article is distributed under the terms of the Creative Commons Attribution License which permits any use, distribution, and reproduction in any medium, provided the original author(s) and the source are credited.

\section{References}

1. Matsushita Y, Inoue Y, Shida M, Nojima Y (1999) Development of two-level codend trawl with bycatch exclusion window in a coastal trawl fishery. Nippon Suisan Gakkaishi 65:673-679 (in Japanese with English abstract)

2. Matsushita Y, Nojima Y, Inoue Y (1999) Development of species separation devices for coastal trawl. Nippon Suisan Gakkaishi 65:11-18 (in Japanese with English abstract)

3. Horie M, Yasuda M, Hashimoto H (2001) Development of seine net for separating snow crab from flatfish. Nippon Suisan Gakkaishi 67:444-448 (in Japanese with English abstract)

4. Inoue $\mathrm{Y}$, Kumazawa $\mathrm{T}$, Adachi $\mathrm{T}$ (2003) Echizen design of coastal selective seine net. Tech Rept Nat Res Inst Fish Eng 25:27-32 (in Japanese with English abstract)

5. Kajikawa Y, Fujiishi A, Inoue S, Nagamatsu K, Hamano A (1998) Preliminary trawling tests using a two-level beam trawl with square mesh separator and its separation efficiency. Nippon Suisan Gakkaishi 64:189-196 (in Japanese with English abstract)

6. Kajikawa Y, Fujiishi A, Nagamatsu K, Tokai T, Matuda K (1999) Species- and size-selectivity of SURF-BRD trawl. Nippon Suisan Gakkaishi 65:278-287 (in Japanese with English abstract)

7. Kajikawa Y, Hu F, Tokai T, Matuda K (2001) Model experiments of improved SURF-BRD trawl. Nippon Suisan Gakkaishi 67:710-716 (in Japanese with English abstract)

8. Kajikawa Y, Tokai T, Hu F (2009) Improvement of species- and size-separation in SURF-BRD with high encounter probability of marine organisms. Nippon Suisan Gakkaishi 75:219-229 (in Japanese with English abstract)

9. Tokai T, Omoto S, Sato R, Matuda K (1996) A method of determining selectivity curve of separator grid. Fish Res 27:51-60

10. Tokai T (1998) Trawl with separator-panel for by-catch reduction and evaluation methodology of their selective performance. In: Proc Symp Marine Fisheries Beyond the Year 2000 Sustainable Utilization of Fisheries Resources. Keelung, Taiwan, pp 104

11. Zuur G, Flyer RJ, Ferro RST, Tokai T (2001) Modelling the size selectivities of a trawl codend and an associated square mesh panel. ICES J Mar Sci 58:657-671

12. Millar RB, Fryer RJ (1999) Estimating the size-selection curves of towed gears, traps, nets and hooks. Rev Fish Biol Fish 9:89-116 
13. Fonseca P, Campos A, Larsen RB, Borges TC, Erzini K (2005) Using a modified Nordmøre grid for by-catch reduction in the Portuguese crustacean-trawl fishery. Fish Res 71:223-239

14. Fonseca P, Campos A, Mendes B, Larsen RB (2005) Potential use of a Nordmøre grid for by-catch reduction in a Portuguese bottom-trawl multispecies fishery. Fish Res 73:49-66

15. Matsushita Y (2001) Evaluation of selective performance of bycatch reduction devices for towed fishing gear. In: Tokai T, Kitahara $\mathrm{T}$ (eds) Fishing gear selectivity and its application to fisheries resources management. Kouseisya Kouseikaku, Tokyo, pp 62-70 (in Japanese)

16. O’Neill FG, Kynoch RJ, Fryer RJ (2006) Square mesh panels in North Sea demersal trawls. Separate estimates of panel and codend selectivity. Fish Res 78:333-341

17. Mituhasi T, Tokai T, Ercoli R, García JC, Salvini L, Bartozzetti J, Roth R (2000) Estimating codend selectivity and fish escapement from a cover net of an insufficiently small mesh size. Fish Sci 66:327-333

18. Mituhasi T, Kitakado T, Hu F, Tokai T (2005) Modelling the contact probability and size-selectivity of toothed dredges. Fish Sci 71:703-712

19. Kim IO, Mituhasi T, Jo TH, Park CD, Tokai T (2005) Effect of tooth spacing on the contact selection and available selection of a dredge for the equilateral venus clam Gomphina melanaegis. Fish Sci 71:713-720

20. Sakamoto Y (1991) Categorical data analysis by AIC (mathematics and its applications). KTK Scientific Publishers, Tokyo

21. Hiramatsu K (1992) A statistical study of fish population dynamics using maximum likelihood method. Parameter estimation and model selection. Bull Nat Res Inst Far Seas Fish 29:57-114 (in Japanese with English abstract)

22. Tokai T (1997) Maximum likelihood parameter estimates of a mesh selectivity logistic model through SOLVER on MSEXCEL. Bull Jpn Fish Oceanogr 61:288-298 (in Japanese with English abstract)

23. Millar RB, Walsh SJ (1992) Analysis of trawl selectivity studies with an application to trouser trawls. Fish Res 13:205-220

24. Walsh SJ, Millar RB, Cooper CG, Hickey WM (1992) Codend selection in American plaice: diamond versus square mesh. Fish Res 13:235-254

25. Petrakis G, Stergiou KI (1997) Size selectivity of diamond and square mesh codends for four commercial Mediterranean fish species. ICES J Mar Sci 54:13-23

26. He P (2007) Selectivity of large mesh trawl codends in the Gulf of Maine: I. Comparison of square and diamond mesh. Fish Res 83:44-59

27. Tokai T (1993) Fisheries management of a small shrimp trawl in the Seto inland sea. Bull Nansei Natl Fish Inst 26:31-106 (in Japanese with English abstract)
28. Yamasaki A, Ohki S, lizuka S (2001) Mesh selectivity for willowy flounder Tanakius kitaharai determined by a beam trawl fishing experiment. Nippon Suisan Gakkaishi 67:1082-1088 (in Japanese with English abstract)

29. Frandsen RP, Madsen N, Krag LA (2010) Selectivity and escapement behaviour of five commercial fishery species in standard square- and diamond-mesh codends. ICES J Mar Sci 67:1721-1731

30. Tokai T, Ito H, Yamaguchi Y (1989) A preliminary study on mesh selectivities of small trawl nets to three flatfish species. Bull Nansei Reg Fish Res Lab 22:29-34 (in Japanese with English abstract)

31. Yamaguchi Prefecture, Fukuoka Prefecture, Oita Prefecture (1989) Report on research projects for the advancement of the fishing industry and development of appropriate management technologies (Suonada Region) pp. 1-310 (in Japanese)

32. Zhenlin L, Horikawa H, Tokimura M, Tokai T (1999) Effect of cross-sectional shape of fish body on mesh selectivity of trawl codend. Nippon Suisan Gakkaishi 65:441-447 (in Japanese with English abstract)

33. Pingguo H (2010) Behavior of marine fishes: capture processes and conservation challenges. Wiley-Blackwell, Oxford

34. Tokai T, Sakaji H (1993) Mesh selectivity of a shrimp beam trawl for tora velvet shrimp Metapenaeopsis acclivis, kishi velvet shrimp Metapenaeopsis dalei and smooth shell shrimp Parapenaeopsis tenella. Bull Nansei Reg Fish Res Lab 26:21-30 (in Japanese with English abstract)

35. Sakaji H (1995) Sand burrowing ability of four species of shrimps, Metapenaeopsis acclivis (Rathbun), M. barbata (De Haan), M. dalei (Rathbun) and Trachypenaeus curvirostris (Stimpson). Bull Nansei Natl Fish Res Inst 28:1-7 (in Japanese with English abstract)

36. Vance DJ (1992) Activity patterns of juvenile penaeid prawns in response to artificial tidal and day-night cycles: a comparison of three species. Mar Ecol Prog Ser 87:215-226

37. Primavera JH, Lebata J (1995) Diel activity patterns in Metapenaeus and Penaeus juveniles. Hydrobiologia 295:295-302

38. Novak M (2004) Diurnal activity in a group of gulf of Maine decapods. Crustaceana 77:603-620

39. Inoue S, Nagamatsu K, Fujiishi A, Abe O (1994) Discards in the small trawl fishery off the west coast of Shimonoseki. J Shimonoseki Univ Fish 42:109-118 (in Japanese with English abstract)

40. Sakai T (2009) Study on the fisheries biology of lizardfishes, in the East China Sea and in Tsushima/Korea. Strait Bull Fish Res Agen No. 28, 1-45 (in Japanese with English abstract)

41. Sakai T, Yoneda M, Tokimura M, Horikawa H, Matsuyama M (2010) Sexual maturity and spawning of the lizard fish Saurida umeyoshii in the East China Sea. Nippon Suisan Gakkaishi 76:1-9 (in Japanese with English abstract) 